\title{
Kritiske hjertefeil hos nyfødte overses
}

\author{
Kritiske medfødte hjertefeil overses ikke sjelden hos nyfødte. Det leder oftest til at barnet reinnlegges med \\ en livstruende sirkulasjonskollaps. Vi trenger bedre strategier for tidlig diagnose av slike feil.
}

\author{
Kjersti Jystad Postmyr \\ Eva Tegnander \\ Alf Meberg \\ alfmeberg@yahoo.no
}

Kritiske medfødte hjertefeil vil ubehandlet lede til utvikling av sirkulatorisk kollaps og død få dager eller uker etter fødselen. Prevalensen er angitt til 1-2 per 1000 levendefødte (1-3). I Norge fødes ca. 70 barn hvert år med kritiske hjertefeil (1). Problemstillingen er derfor ikke sjelden. En del av feilene overses både ved pre- og postnatale rutineundersøkelser. Ifølge engelske studier er en tredel av barn med potensielt livstruende hjertefeil udiagnostisert når de skrives ut fra sykehus etter fødselen (4). Noen av disse dør før de kommer til behandling (5). Problemet er også velkjent i vårt land både fra kliniske studier $(1,6)$ og dagspressen (7). Det er derfor en viktig oppgave for helsearbeidere innen foster- og nyfødtmedisin å oppdage kritiske hjertefeil før barnet utvikler alvorlige symptomer.

\section{Prenatal diagnostikk}

Mange kritiske hjertefeil oppdages ved rutinemessig ultralydundersøkelse av fosteret rundt uke 18 i svangerskapet, noe som gir mulighet for fødsel i sykehus med høyspesialisert kardiologisk og hjertekirurgisk kompetanse. Ved Nasjonalt senter for fostermedisin ble i en uselektert populasjon i perioden 1991-2001 57\% av komplekse feil funnet ved firekammerbilde og kartlegging av utløpet av de store arteriene fra hjertet (8). En evaluering av perioden 2002-12 pågår nå. I dag anbefaler senteret fem standardsnitt, som beskrevet av Yagel og medarbeidere (9). I en observasjonsstudie fra Stavanger i årene 2006-09 var deteksjonsraten $67 \%$ ved tillegg av fargedoppler (10). Insidensen av hjertefeil i populasjonen var ukjent og resultatene må tolkes med forsiktighet. International Society of Ultrasound in Obstetrics and Gynecology anbefaler i sine siste retningslinjer fra mars 2013 bruk av fargedoppler ved ultralydundersøkelsen av fosterhjertet (11). Studier viser at ultralydundersøkelse rundt uke 12 i svangerskapet har potensial til å påvise opp mot $45 \%$ av alvorlige hjertefeil hos foster med normale kromosomer og nakkeoppklaring over 95prosentilen (12).

Studier over prenatale hjerteundersøkelser vil inkludere avbrutte svangerskap og dødfødsler med komplekse feil (ofte kombinert med andre alvorlige syndromer og misdannelser $)(8,10)$ og vil dermed vise en høyere deteksjonsrate enn for tilsvarende hjertefeil blant levendefødte. Det er også forskjeller i deteksjonsraten mellom ulike sentre, knyttet til kompetanse og ressurser (13). I overenstemmelse med dette var prenatal deteksjonsrate av kritiske hjertefeil $28 \%$ for hele den norske populasjonen av nyfødte i årene 2005-06 (1). Enkelte kritiske hjertefeil (f. eks. abnormalt innmunnende lungevener, transposisjon av de store arterier, venstresidige obstruktive feil) overses hyppig fordi de kan være vanskelig å oppdage ved fosterundersøkelsen (13). Derfor vil en vesentlig del av de kritiske feilene måtte diagnostiseres postnatalt.

\section{Klinisk rutineundersøkelse av nyfødte}

Alle nyfødte undersøkes rutinemessig av lege før hjemreise, vanligvis i første eller andre levedøgn. De fleste undersøkes bare én gang. For å kunne identifisere symptomer på mulig hjertefeil er det viktig med en systematisk undersøkelse (hudfarge, respirasjonsmønster, lyskepuls, hjertefrekvens, hjertetoner og bilyd), og ikke bare en rask auskultasjon. Bilyd hos nyfødte er vanlig, og representerer relativt hyppig organisk hjertefeil (14). Omvendt har ca. halvparten av barn med hjertefeil ikke bilyd som gir mistanke om patologi (15). Kritiske feil oppdages oftest klinisk før hjemreise pga. bilyd eller cyanose. Å vurdere arteriell oksygenmetning på bakgrunn av hudfargen er imidlertid vanskelig (16) og barnet kan ha en kritisk hjertefeil med nedsatt arteriell oksygenmetning uten synlig cyanose. Hos nyfødte som har funn som kan gi mistanke om hjertefeil, er det viktig at barnet ikke sendes hjem før ytterligere undersøkelser (vanligvis ekkokardiografi) har kunnet bekrefte eller avkrefte mistanken.

\section{Pulsoksymetriscreening}

Det er gjort flere store prospektive multisenterstudier på pulsoksymetriscreening av nyfødte de senere årene, bl.a. i Norge
(17) og Sverige (2). Disse viser sammenliknbare resultater med hensyn til nøyaktighet i deteksjon av kritiske hjertefeil. I en stor metaanalyse av Thangaratinam og medarbeidere der 13 studier med totalt 229421 nyfødte inngikk, inklusive de to nordiske studiene, konkluderte forfatterne med at pulsoksymetriscreeningen var høygradig spesifikk for deteksjon av slike feil og tilfredsstiller kriteriene for universell screening (18). Positiv prediktiv verdi ved bruk av pulsoksymetri er minst sju ganger høyere enn ved klinisk undersøkelse alene (2). Kombinert med klinisk rutineundersøkelse øker oppdagelsesraten før hjemreise ytterligere (17) og reduserer antall oversette tilfeller til $8-12 \%(1,2)$. Metodens enkelhet og lave kostnader er beregnet å gi en positiv kostnad-nytte-effekt (19).

Pulsoksymetriscreening har varierende sensitivitet for deteksjon av ulike typer kritiske hjertefeil. Obstruktive tilstander i venstre ventrikkel eller aortabuen har ikke sjelden en oksygenmetning i eller nær normalområdet og overses derfor hyppigst $(1,2)$. Spesielt er coarctatio aortae en utfordring, der sensitiviteten for deteksjon er ca. $50 \%$ (20).

Viktige spørsmål i dag er hvorvidt pulsoksymetriscreeningen skal utføres ved kun én måling på fot (postduktalt) eller om det skal måles samtidig både på høyre arm (preduktalt) og fot med vektlegging av differansen $i$ oksygenmetningen. I en svensk studie vektla de-Wahl Granelli og medarbeidere en differanse på $>3 \%$ i metningen mellom arm og fot som tegn på kritisk hjertefeil, selv om metningen begge steder var $\geq 95 \%$, i tillegg til den generelle grenseverdien på $\mathrm{SpO}_{2}<95 \%$ (2). En amerikansk arbeidsgruppe foreslo i 2011 retningslinjer for pulsoksymetriscreening der en slik differanse vektlegges (21). Kombinert pre- og postduktal måling har trolig noe bedre sensitivitet for deteksjon av koarktasjoner, men er som screeningmetode litt mer komplisert enn måling bare på fot.

Det foreligger ulike anbefalinger om hvor lang tid etter fødselen screeningen bør utføres. I USA anbefales screening før hjemreise, men fortrinnsvis etter 24 timers alder for å redusere andelen falskt positive (22). Andelen falskt positive er imidlertid relativt lav og ble i to store undersøkelser med screening første levedøgn funnet 


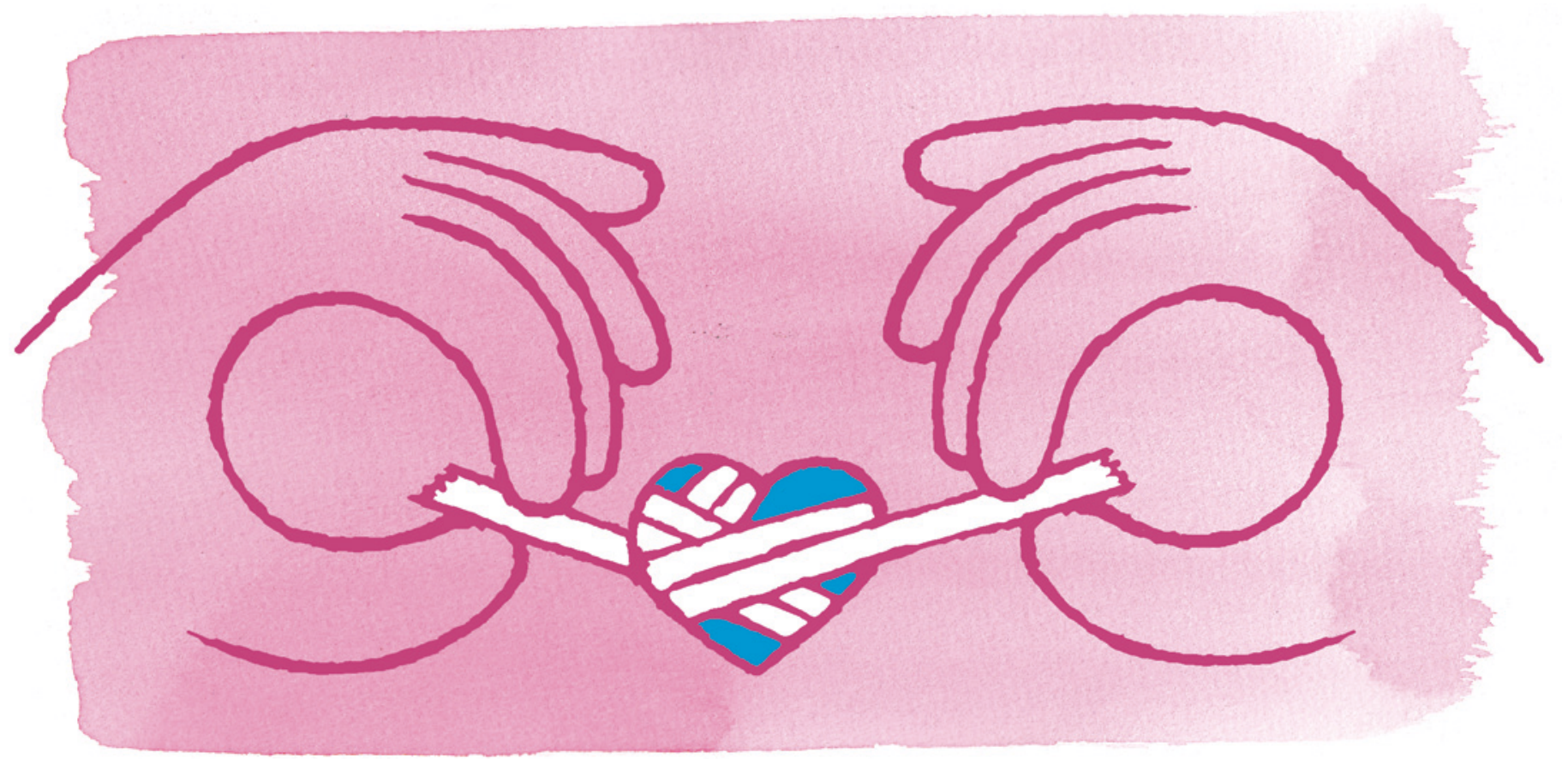

Illustrasjon @ Superpop

å være henholdsvis $0,6 \%$ og $0,8 \%(17,23)$. Falskt positive gir lite ekstra bruk av ressurser til «unødvendig» ekkokardiografi. For eksempel vil en falskt positiv rate på $0,6 \%$ bare medføre én ekstra ekkokardiografi per måned i en institusjon med 2000 nyfødte per år. Falskt positive representerer dessuten i stor utstrekning potensielt alvorlige ikke-kardiale sykdommer, spesielt infeksjoner og lungesykdommer. I den norske studien hadde nesten $50 \%$ av barna som testet falskt positivt slike tilstander (17). Fra England ble tilsvarende $24 \%$ funnet å ha tilstander som krevde umiddelbar intervensjon (23).

En negativ konsekvens av å foreta screeningen etter første levedøgn er tap av tid i diagnostikken av kritiske hjertefeil samt ikke-kardiale tilstander med nedsatt oksygenmetning. I en norsk studie oppdaget sykehus som screenet med pulsoksymetri kritiske hjertefeil raskere før hjemreise enn sykehus som ikke screenet (median henholdsvis 6 timer og 16 timer) (1). Med tidlig hjemreise fra barselavdelingen (en del utskrives allerede første levedøgn) er det også fare for at ikke alle blir testet. Helsedirektoratet har tross dette i sine retningslinjer for barselomsorgen fra juni 2013 anbefalt pulsoksymetriscreening først når barnet er $\geq 24$ timer (24).

En utfordring er det desentraliserte fødemønsteret i Norge, der halvparten av fødeinstitusjonene har under 500 fødsler per år. Etter vår mening vil pulsoksymetriscreening gi mindre fødesteder med begrensede ressurser bedre mulighet til tidlig deteksjon av kritiske hjertefeil, slik at de raskt kan overflytte barnet til avdeling med barnekardiologisk kompetanse.

\section{Ekkokardiografi}

Ved universell ekkokardiografi av nyfødte vil man kunne oppdage de aller fleste hjertefeil før hjemreise fra sykehuset. I en irsk undersøkelse fant Sands og medarbeidere at over dobbelt så mange hjertefeil ble oppdaget ved ultralydscreening av tilsynelatende friske nyfødte som i kontrollgruppen (kun klinisk undersøkelse) (25). Ingen kritiske feil ble diagnostisert etter utskrivningen. Universell ekkokardiografi av nyfødte er imidlertid ressurskrevende og har en høy rate falskt positive (26). En uriktig hjertefeildiagnose hos et nyfødt barn skaper unødig engstelse for foreldrene. Det vil også være behov for oppfølgende kontroller. Målrettet ekkokardiografi av risikogrupper er i dag mest realistisk. Dette gjelder barn der det prenatalt er påvist mulig hjertepatologi, barn med syndromer eller utviklingsavvik, der søsken har hjertefeil, der det er kliniske funn ved nyfødtundersøkelsen eller barnet har nedsatt oksygenmetning ved pulsoksymetriscreeningen.

\section{Konklusjoner}

Det er viktig med oppdaterte retningslinjer for systematisk hjertescreening pre- og postnatalt ved norske fødeinstitusjoner. Dette inkluderer både retningslinjer for ultralydundersøkelse av fosteret og for utredning ved mistanke om hjertefeil hos nyfødte, inkludert universell pulsoksymetriscreening første levedøgn. Hos barn som ikke har åpenbare ekstrakardiale tilstander som forklarer nedsatt oksygenmetning, må det raskt utføres ekkokardiografi. I tillegg må ekkokardiografi tilbys barn i risikogruppene for medfødt hjertefeil.

\section{Kjersti Jystad Postmyr (f. 1989)}

er medisinstudent ved Norges teknisk-naturvitenskapelige universitet.

Forfatter har fylt ut ICMJE-skjemaet og oppgir ingen interessekonflikter.

\section{Eva Tegnander (f. 1955)}

er jordmor og førsteamanuensis med doktorgrad på prenatal oppdagelse av hjertefeil og arbeider ved Norges teknisk-naturvitenskapelige universitet og Nasjonalt senter for fostermedisin, Trondheim.

Forfatter har fylt ut ICMJE-skjemaet og oppgir ingen interessekonflikter.

\section{Alf Meberg (f. 1942)}

er spesialist i barnesykdommer og tidligere overlege ved Sykehuset i Vestfold. Han har doktorgrad om medfødte hjertefeil. Forfatter har fylt ut ICMJE-skjemaet og oppgir ingen interessekonflikter.

\section{Litteratur}

1. Meberg A, Andreassen A, Brunvand L et al. Pulse oximetry screening as a complementary strategy to detect critical congenital heart defects. Acta Paediatr 2009; 98: 682-6.

2. de-Wahl Granelli A, Wennergren M, Sandberg K et al. Impact of pulse oximetry screening on the detection of duct dependent congenital heart 
disease: a Swedish prospective screening study in 39,821 newborns. BMJ 2009; 338: a3037.

3. Liske MR, Greeley CS, Law DJ et al. Report of the Tennessee Task Force on screening newborn infants for critical congenital heart disease. Pediatrics 2006; 118: e1250-6.

4. Wren C, Reinhardt Z, Khawaja K. Twenty-year trends in diagnosis of life-threatening neonatal cardiovascular malformations. Arch Dis Child Fetal Neonatal Ed 2008; 93: F33-5.

5. Abu-Harb M, Hey E, Wren C. Death in infancy from unrecognised congenital heart disease. Arch Dis Child 1994; 71:3-7.

6. Meberg A, Otterstad JE, Frøland G et al. Early clinical screening of neonates for congenital hear defects: the cases we miss. Cardiol Young 1999; 9: $169-74$

7. Stølan J, Dahl ID. Sykehus og leger brøt loven hjertesyk baby døde. VG Nett 5.10.2013. www.vg.no/nyheter/innenriks/ artikkel. php?artid=10127126 (18.12.2013)

8. Tegnander E, Williams W. Johansen OJ et al. Prenatal detection of heart defects in a non-selected population of 30,149 fetuses-detection rates and outcome. Ultrasound Obstet Gynecol 2006; 27 252-65.

9. Yagel S, Cohen SM, Achiron R. Examination of the fetal heart by five short-axis views: a proposed screening method for comprehensive cardiac evaluation. Ultrasound Obstet Gynecol 2001; 17: 367-9

10. Eggebø TM, Heien C, Berget M et al. Routine use of color Doppler in fetal heart scanning in a low-risk population. ISRN Obstet Gynecol 2012; 2012: 496935.
11. Carvalho JS, Allan LD, Chaoui R et al. ISUOG Practice Guidelines (updated): sonographic screening examination of the fetal heart. Ultrasound Obstet Gynecol 2013; 41: 348-59

12. Sotiriadis A, Papatheodorou S, Eleftheriades M et al. Nuchal translucency and major congenital heart defects in fetuses with normal karyotype: a meta-analysis. Ultrasound Obstet Gynecol 2013, 42: 383-9.

13. Friedberg MK, Silverman NH, Moon-Grady AJ et al. Prenatal detection of congenital heart disease. J Pediatr 2009. 155: 26-31, e1.

14. Du Z-D, Roguin N, Barak M. Clinical and echocardiographic evaluation of neonates with heart murmurs. Acta Paediatr 1997; 86: 752-6.

15. Ainsworth SB, Wyllie JP. Wren C. Prevalence and clinical significance of cardiac murmurs in neonates. Arch Dis Child Fetal Neonatal Ed 1999; 80: F43-5.

16. O'Donnell CPF, Kamlin COF, Davis PG et al. Clinical assessment of infant colour at delivery. Arch Dis Child Fetal Neonatal Ed 2007; 92: F465-7.

17. Meberg A, Brügmann-Pieper S, Due R Jr et al. Firs day of life pulse oximetry screening to detect congenital heart defects. J Pediatr 2008; 152: 761-5.

18. Thangaratinam S, Brown K, Zamora J et al. Pulse oximetry screening for critical congenital heart defects in asymptomatic newborn babies: a sys tematic review and meta-analysis. Lancet 2012; 379: 2459-64

19. Peterson C, Grosse SD, Oster ME et al. Costeffectiveness of routine screening for critical congenital heart disease in US newborns. Pediatrics 2013; 132: e595-603.

20. Valmari P. Should pulse oximetry be used to screen for congenital heart disease? Arch Dis Child Fetal Neonatal Ed 2007: 92: F219-24.

21. Kemper AR, Mahle WT, Martin GR et al. Strategies for implementing screening for critical congenital heart disease. Pediatrics 2011; 128: e1259-67.

22. Mahle WT, Newburger JW, Matherne GP et al. Role of pulse oximetry in examining newborns for congenital heart disease: a scientific statement from the AHA and AAP. Pediatrics 2009; 124: 823-36.

23. Ewer AK, Middleton LJ, Furmston AT et al. Pulse oximetry screening for congenital heart defects in newborn infants (Pulse Ox): a test accuracy study. Lancet 2011; 378: 785-94.

24. Nytt liv og trygg barseltid for familien. Kortversjon av retningslinjer for barselomsorgen. Nasjonale faglige retningslinjer. IS-2086. Oslo: Helsedirektoratet, 2013

25. Sands A, Craig B, Mulholland C et al. Echocardiographic screening for congenital heart disease: a randomized study. J Perinat Med 2002; 30 : $307-12$.

26. Knowles R, Griebsch I, Dezateux C et al. Newborn screening for congenital heart defects: a systematic review and cost-effectiveness analysis. Health Technol Assess 2005; 9: 1-152, iii-iv.

Mottatt 1.11. 2013, første revisjon innsendt 18.11 2013, godkjent 18.12. 2013. Redaktør: Matilde Risopatron Berg.

Podkast på www.tidsskriftet.no 